\title{
The Success and Struggles of Physical Education Teachers While Teaching Online During the COVID-19 Pandemic
}

\author{
Erin Centeio \\ University of Hawaii at Manoa \\ Heather Erwin \\ University of Kentucky
}

\author{
Kevin Mercier \\ Adelphi University \\ Risto Marttinen \\ George Mason University
}

\author{
Alex Garn \\ Louisiana State University \\ John Foley \\ State University of New York at \\ Cortland
}

\begin{abstract}
The purpose of this study was to investigate physical education teachers' perceptions of implementing online physical education during the COVID-19 pandemic as well as to explore their needs with regard to support for future teaching experiences. A total of 4,302 teachers completed four open-ended questions as part of a larger survey. Deductive and inductive qualitative analysis led to three themes: (a) Teachers' Proud Moments, (b) Help! So Many Obstacles, and (c) Future Challenges. Teachers stated many successes and challenges that they experienced through the COVID-19 pandemic. Many items specifically focused on use and access to technology, student participation, and meeting students' needs in various ways. Results can provide guidance for how to address the essential components of physical education in the online environment. In addition, results may provide insight to those who educate, train, and prepare teachers to teach in a virtual and/or physically distanced environment.
\end{abstract}

Keywords: barriers, PE teachers experiences, school, qualitative, quality remote PE instruction

COVID-19, the respiratory disease caused by the SARS-CoV2 virus, emerged as a global pandemic during spring 2020, forcing schools across the world into changing the ways in which they delivered instruction. As schools have been suggested as a place to help children obtain 60 min or more of physical activity (PA; IOM, 2013), moving to an online environment caused concern for not only educational outcomes (Eyles, Gibbons, \& Montebruno, 2020) but also current and future health outcomes of children (Rundle, Park, Herbstman, Kinsey, \& Wang, 2020). Initial studies on the impact of COVID-19 suggest decreased levels of children's PA and increased rates of children's obesity (An, 2020; Dunton, Do, \& Wang, 2020; Guerrero et al., 2020; Rundle et al., 2020). These studies indicate increased sedentary behaviors, lack of PA opportunities outside of school time, and lack of physical education (PE) as contributing factors to the identified undesirable health outcomes.

$\mathrm{PE}$ is a natural place to address public health concerns (McKenzie \& Lounsbery, 2014) including decreases in PA resulting from the pandemic - especially in light of the current goal of PE to assist students in acquiring "the knowledge, skills and confidence to enjoy a lifetime of healthful physical activity" (SHAPE America [Society of Health and Physical Educators], 2020). The

Centeio is with the Department of Kinesiology and Rehabilitation Science, University of Hawaii at Manoa, Honolulu, HI, USA. Mercier is with the Health and Sport Sciences, Adelphi University, Garden City, NY, USA. Garn is with the School of Kinesiology, Louisiana State University, Baton Rouge, LA, USA. Erwin is with the Department of Kinesiology and Health Promotion, University of Kentucky, Lexington, KY, USA. Marttinen is with the College of Education and Human Development, George Mason University, Manassas, VA, USA. Foley is with the Department of Physical Education, State University of New York at Cortland, Cortland, NY, USA. Centeio (ecenteio@ hawaii.edu) is corresponding author. pandemic-initiated shift to online instruction provided numerous challenges to PE teachers. In PE, a traditionally marginalized subject (Richards, Gaudreault, Starck, \& Woods, 2018), teachers, with little to no training, lacked expertise in remote PE instruction and resorted to "trial-and-error" methods (Jeong \& So, 2020). Though research on effective or quality instruction in PE, aligned with student learning outcomes and promoting achievement of standards has been presented previously (Rink, 2013), the overwhelming majority of this research focuses on in-person PE instruction. Research suggests that oftentimes, there is a different focus or goal of in-person PE versus online PE, with in-person PE primarily focusing on achieving competency in a variety of motor skills as compared with the primary focus online of improved health behaviors and fitness levels (Goad \& Jones, 2017). The benefits that students receive from online PE have been identified; however, research in this area has been limited, and issues with teacher training, student accountability, and the lack of a comprehensive focus have been presented (Daum \& Buschner, 2012; Mohnsen, 2012: Williams, 2013). Therefore, it is important that we understand how online PE occurred during the COVID-19 pandemic and although it is situation-specific, we need to document it and use this information to inform the future of online PE.

At the onset of the COVID-19 pandemic in the United States, schools were shut down with little notice and teachers were expected to move their curriculum online. We anticipate that PE teachers were no different from other subject area teachers, as many were struggling to not only figure out how they were going to disseminate information in an online format, but also to determine what segments of their current curriculum could "transfer" to an online environment (Marshall, Shannon, \& Love, 2020). Although no known research is conducted on the topic, the authors imagine that teachers were considering best practices in PE; however, they 
were juggling what they know in a general setting with how to effectively disseminate in this "new to them" online environment.

While research concerning quality in-person PE instruction is well established, much remains unknown regarding remote PE instruction. The current pandemic has forced many schools to embark on an online journey, with remote or hybrid instruction imminent for most of the 2020-2021 school year. It seems extremely likely that some form of remote instruction in PE will remain even after the pandemic passes. An important first step in identifying effective remote instruction methodologies and modalities is speaking with PE teachers, who were forced to "learn on the go" during the pandemic. Although the pandemic presents a unique situation, understanding the initial experiences of teachers in moving to a remote learning environment and identifying the challenges and facilitators to successful remote instruction is needed to help teachers and other PE professionals design effective learning experiences in the future. Therefore, the purpose of this study was to investigate PE teachers' perceptions of implementing PE during the COVID-19 pandemic as well as to explore their needs with regard to support for future teaching experiences.

\section{Method}

A total of 4,302 PE teachers participated in the study, of which 2,238 (52\%) taught elementary, 597 (14\%) middle school, 469 $(11 \%)$ high school, and 998 (23\%) multilevel. Multilevel was any combination that spanned across both the elementary $(\mathrm{K}-5)$ and secondary (6-12) grade bands. Teachers were categorized as $23 \%$ rural, $35 \%$ suburban, and $42 \%$ urban. All 50 U.S. states were represented, with $23 \%$ of teachers from the Northeast, $25 \%$ from the Midwest, 33\% from South, and 19\% from the West.

\section{Data Collection and Data Sources}

University of Hawai'i at Mānoa institutional review board approval was received to conduct secondary data analysis of a survey distributed by the Online Physical Education Network (OPEN) www.openphyed.org. OPEN provides standards-based PE curricula in a free online environment. During the COVID-19 pandemic, OPEN provided weekly PE content for teachers that focused on getting children active while quarantined at home.

To better understand the needs of teachers using their resources, OPEN initiated a survey to start planning how to support teachers and schools during the following school year. As this is a secondary analysis of data, the survey was designed for professional development (PD) and to gather information to guide resource development. In addition to multiple choice questions that focused on planning for next year (Mercier et al., 2021), the survey included four open-ended questions that were the focus of this research. The open-ended questions focused on teachers' successes, barriers, PD, and concerns. The questions were: "What has been your biggest struggle in a distanced learning environment?" "What has been your biggest success in a distanced learning environment?" "What is your biggest PD need for next school year?" and "What is your biggest overall concern as you plan and prepare for next school year?" The survey, which was designed using Google forms, was distributed in OPEN's weekly online newsletters. The link was included in the newsletter for a total of 2 weeks in May. The OPEN platform consisted of teachers, parents, administrators, higher education faculty, preservice teachers, and other groups, but only data from teachers who taught PE in a $\mathrm{K}-12$ setting were included in the current study. As of May 31,
2020, the OPEN database showed 83,988 registered users (people who sign up for free access to content and email notices). It was difficult to calculate a response rate given limitations with the database (e.g., open-ended answers for occupation) as well as knowing how many OPEN users are currently active and viewed the newsletter. We estimate that there are approximately 58,000 PE teachers in the database, resulting in an estimated response rate of $13.48 \%$. Although this response rate is fairly low, given the unprecedented time, coupled with the uniqueness of the data collected and the broad representation of teachers, we proceeded with the qualitative analysis.

Quantitative survey results from this survey have been reported elsewhere (Mercier et al., 2021). Open-ended survey responses constitute the qualitative data for this study. Although the data source for this study is singular, it does consist of a large sample of teachers that provided over 17,000 data points. Given the substantial amount of data, the unprecedented time in the world with COVID-19, and the rigorous analysis and strategies to enhance trustworthiness explained below, the research team moved forward with this one data source, and this is acknowledged as a study limitation.

\section{Data Analysis and Trustworthiness}

Using a collaborative data analysis approach (Richards \& Hemphill, 2018), three researchers worked together to analyze the data from the four open-ended questions that were included in the questionnaire. The collaborative qualitative analysis technique used a six-step process that included preliminary organization and planning, deductive and inductive coding, development of a preliminary codebook, pilot testing of the codebook, final coding process, and reviewing the codebook and finalizing themes. Researchers decided to use deductive coding upfront where all of the data were left affiliated with the specific questions determined by the survey. Because the questions were very pointed, leaving the data within these four categories or deductive codes made sense. Acknowledging the deductive coding, researchers began inductive coding where they read the data multiple times and developed initial codes within each topic based on the deductive codes. A researcher team meeting was conducted to discuss the initial themes and codes. Using the first version of the codebook, the researchers piloted the codebook and coded $1 \%$ of the database. During the second meeting, all $1 \%$ of the data were examined by each specific code and discussions were had about discrepancies. In addition, the codes were discussed and revised at this time. In the first round of pilot testing of the codebook, researchers had interrater reliability of $77 \%$. Based on the revised codebook, the researchers coded an additional $1 \%$ of the data. On the second round of data coding, the researchers achieved an $85 \%$ interrater reliability. At this point, the researchers coded the remaining $98 \%$ of the database. If questions arose throughout the coding process, researchers immediately discussed the questions as a group, made a decision, and continued coding. Once all data were coded, the research team gathered to review the coded data and create a thematic structure that was representative. There were approximately 10 inductive codes within each deductive coding category, and a total of 17,208 data points were coded.

In order to create the thematic structure, researchers reviewed the coded data in two unique ways. First, each selective coding group was analyzed quantitatively by counting the number of codes for each category. A number was tabulated for each code to determine which codes emerged as the most mentioned topics 
by teachers. Based on the quantitative counts and inductive coding, themes were created. In addition, Wordle was used to confirm the themes that were created but not included in the published manuscript due to space limitations.

It was difficult for traditional trustworthiness strategies to be applied due to the nature of the de-identified secondary data analysis coupled with the COVID-19 pandemic. However, the use of multiple data analysts that occurred is a recognized strategy for enhancing trustworthiness (Elo et al., 2014), and in addition to the rigorous data analysis process, researchers kept an audit trail and researcher journal during the data coding and thematic analysis process. They also searched for negative cases throughout the data analysis process, including once final themes were set, in order to ensure the themes that emerged were representative of the data.

\section{Results}

We present the Results section in three overarching themes based on the initial deductive coding: (a) Teachers' Proud Moments; (b) Help! So Many Obstacles, and (c) Future Challenges.

\section{Theme 1: Teachers' Proud Moments}

When teachers were asked to share what successes they had while teaching during the COVID-19 pandemic, many had plenty of things that they spoke of. Teachers most commonly spoke of about three specific areas including overcoming and learning technology (28\%), engaging students in online learning (20\%), and their ability to create good content for students (15\%).

Over $28 \%$ of teachers said overcoming and learning technology was one of their biggest successes during the COVID-19 pandemic. One teacher stated simply that their biggest success was "learning how to use technology in PE" (Teacher 1733), while another went into more detail to say, "My growing knowledge of the technology available (still have so much to learn) and discovering the resources other teachers are willing to share" (Teacher 537). Teachers often cited the use of external learning platforms that they learned to use, such as Zoom, Flipgrid, Google Classroom, and YouTube. These platforms allowed teachers to post and record videos to share with students and were a common theme within this category. For example, one teacher stated, "My biggest success was figuring out some technology basics to video, upload to YouTube, work in Google Classroom and Dojo" (Teacher 2664), while another stated that their biggest success was "FlipGrid! I've had great student response ... . It's also an easy way to teach a basic skill and for them to show me them practicing said skill (i.e. hockey, juggling, throwing)" (Teacher 1833).

Many teachers also reported teaching through video conferencing apps like Zoom to run live classes and cited learning to navigate this new form of teaching as a victory. One teacher stated, "Connecting with students via Zoom [was their biggest success] and the OPEN at-home lessons have provided excellent resources to use/send to students" (Teacher 4132). Finally, one teacher talked about the digital experience more broadly stating that "being able to transition to a digital learning environment has been my success. To go from the normal teaching style and switching with little preparation has been a learning experience" (Teacher 2397).

Another success that many teachers (20\%) mentioned was engaging students in online learning. Teachers were enthusiastic about receiving videos and assignments from their students demonstrating activities and showing them being physically active at home. Many teachers were happy to have students engage in synchronous video classes, as well as participating in the daily activities. One teacher stated their biggest success "was being able to reach most of my students either through written communications such as messaging or email as well as live chats and zoom/ meet software" (Teacher 3834). Another was encouraged as they stated that "my students that have been participating are giving me really good feedback about the types of activities they enjoy and that is helping me find resources to keep them engaged" (Teacher 4042). Similarly, Teacher 1390 stated, "I have had at least 70\% engagement and have received videos of students learning to ride bikes, learning to ride without training wheels, learning to skate or improving their skating skills, and the creativity of my families is incredible!" Yet another gave their student options, which they reported as successful because "the number of students who sign on to my live zoom classes [is my biggest success]. I provide it as an added feature. The students have an additional assignment that they get at the beginning of the week. Parents have also emailed me about how much their children love the interaction" (Teacher 3351). However, as will be noted in the next section, not all teachers were able to connect with all of their students.

Finally, the teachers' ability to create good content for students also seemed to be a major accomplishment for them. Good content was described by teachers in many different ways and included content like engaging and inspiring videos, custom videos for their own PE classes, challenge activities, and resources from peers and companies (including OPENPhysEd which provided content and ran a virtual field day). One teacher mentioned, "Finding activities for every age level to complete using household items and still being able to meet grade level standards" (Teacher 302). Another stated, "I believe my lessons have been a big success. The students that are doing them are enjoying them. They really loved the OPEN virtual field day" (Teacher 3504). Teacher 346 shared, "being able to use resources that have been shared by others as well as creating and adapting things on my own to create video lessons." Another teacher stated, "joining weekly meetings with all my classes, providing a monthly PE interactive calendar, hosting fitness Friday's videos showing the PE staff introducing fun fitness ideas and just being silly" (Teacher 3308). Overall, the teachers noted that good content was "fun," "engaging," and typically consisted of some type of video activity.

\section{Theme 2: Help! So Many Obstacles}

The second theme focuses on issues that teachers faced while teaching during the pandemic and the needs that they have for PD to help better prepare them for PE in the future. In teacher responses, there was an abundance of calls for help in relation to how to best provide quality PE during the COVID-19 pandemic and beyond.

As stated above in Theme 1, teachers were happy with the amount of participation that they received from their students who logged on and attended class or turned in assignments given the situation and what was going on in the world. However, there was also a significant number of teachers who expressed concern over the lack of participation of students. The concern revolved around teachers not knowing if students were engaging in their lessons as well as the lack of trust demonstrated by teachers regarding their students' submission of work. Teachers were assigning work, but the response rate of their students was low, and this was a hard concept to deal with. For example, one teacher stated, "I am only getting $35-40 \%$ response rate-PE is NOT graded. We use S (satisfactory)/U (unsatisfactory) categories only. Therefore, unless 
they click on our folder in their learning management system, the assignment goes unnoticed" (Teacher 505).

Similarly, another teacher noted that they struggled with "receiving assignments back from students and student participation for assigned tasks" (Teacher 1180). Others talked about how it was hard to get students to turn in assignments: "Kids not doing the assignments, exercises" (Teacher 2492) and "getting students to do the assignments" (Teacher 2053). Many teachers attributed poor student engagement to a lack of clear school, district, or state-level policies, either specific to PE or across-the-board for all subject areas. With the lack of policy or a mechanism for enforcement, it was hard to hold students accountable. Teacher 237 stated, "Participation. After administration said it wasn't for a grade, participation went downhill fast!" Another teacher stated, "My biggest struggle is the number of participants from week to week. I saw a big drop in attendance once my state announced that elementary schools wouldn't be giving grades" (Teacher 835). Accountability seemed to be an underlying issue here; thus, many students did not participate, and the teachers found it nearly impossible to hold students accountable for completing any of the work or participating in the lessons.

Meeting the needs of all students was also on the minds of teachers when it came to concerns that they had when teaching during COVID-19. Teachers expressed concern about "reaching" or getting the content to students, especially in areas where many did not have Internet. For example, one teacher stated their biggest struggle was, "Reaching all students; Lack of data/proof students are active and actually completing assignments" (Teacher 2183) and others expressed concern about the lack of Internet. One teacher stated that "only $40 \%$ of children have internet" (Teacher 1332), while another said "lack of students that have access to technology/ internet" (Teacher 488). Some teachers demonstrated that they found a way to try and meet the needs of students by printing hard copies of assignments and tasks for students to complete, however, then this presented more barriers as they had no way to collect the information as it was distributed, "I have struggled with communicating with students that do not have technology. However, I printed them out the activity sheets you provided. Those sheets were sent to the student by the district; however, I have no way of checking in on them" Teacher (864).

In addition to struggles specifically around student participation and meeting students' needs, teachers (just under 40\%) expressed the need for additional PD as they did not feel confident with their current skills and providing quality PE. Specifically, teachers were struggling the most with technology issues and resources for teaching in a socially distanced or at-home learning environment. They discussed the need for platform-specific PD (e.g., Zoom, Google Meets, Canvas) as well as training on creating online content including videos. One teacher stated:

Using various platforms to deliver instruction. We were told to deliver via Class Dojo. I also used Facebook. Facebook does not allow the upload of pdf files. Many other districts used google classroom, Seesaw and other platforms. Grading as well. We have to give grades A-F. Not getting a lot of direction from my Admin. (Teacher 2138)

This example makes it evident how frustrated teachers were with the switching of platforms or not knowing how to effectively communicate with students. Other teachers expressed similar frustrations. Teacher 3300 stated,

A unified, district-wide, format [such as Google Classroom] that all teachers will use to push out information to students and parents [is what is needed for PD]. PD would cover education on how to use all of the technologies available to us through that format. As well as education about how to teach our students and parents how to use it.

Other teachers were more general about their needs, but many focused on the need for technology-specific PD. A few examples: "Online distance learning" (Teacher 1334), "learning how to use the tools for distance learning" (Teacher, 1447), and "teaching in an E-learning environment" (Teacher 1535). The need for understanding the role of technology in an online and blended learning environment was at the top of teachers' minds and spanned grade levels, with $35 \%$ of elementary, $41 \%$ of middle school, $46 \%$ of high school, and $36 \%$ of mixed-level teachers expressing this specifically.

Another area that teachers expressed as a need in relation to PD was around PE in general. Even in the midst of COVID-19, it was apparent that $\mathrm{PE}$ teachers didn't receive the same access to contentspecific PD that their classroom teacher peers were afforded. Many (13\% or $\sim 550$ teachers) stated that they just wanted PD that was PEspecific. For example, "The more free webinars the better. Our school district doesn't provide anything for specials. Every time there is PD it is geared toward the grade level teachers and then we are required to attend and get nothing out of it" (Teacher 2157). Similarly, other teachers stated, "Courses that are designed for PE teachers. My district doesn't do any kind of specialty PD for PE or any specials. It's not a high priority in such a small district" (Teacher 1578). Another added, "Having PD geared towards us as physical educators! Most of ours in our district is in a setting with Academic Teachers!" (Teacher 3915). Whether it was training to overcome issues with technology directly and meeting the needs of their students, or the need for future focused PD, teachers expressed that they needed help in providing quality PE for students.

\section{Theme 3: Upcoming Challenges}

Theme 3 focused on the upcoming challenges that teachers faced in the spring/summer of 2020 and moving into the fall semester. Teachers had a lot of concerns about how to teach effectively through COVID-19, and many of their fears focused on the unknown, teaching in a socially distanced manner, and keeping the kids and themselves safe.

The fear of the unknown was frustrating and all-consuming for teachers. Over $35 \%$ expressed that the greatest concern they had about the upcoming year was not knowing what their situation was. Teacher 345 stated that "my district isn't giving us any idea what it might be like so we can begin to prepare in any sort of way," and another stated, "I don't know what to plan [for the fall] because I don't know what the plan is" (Teacher 2235). Other teachers stated how they were in the dark because they didn't know "what the parameters will be" (Teacher 1640) or "if classes will be in-school, distance learning, or a combination of both" (Teacher 1489). Many others, like Teacher 1372, just stated that their biggest concern was "the unknown." These feelings of not knowing what was going to happen were evenly distributed among all levels of teachers with a narrow range of $34 \%$ of mixed-level teachers to $37 \%$ of high school teachers.

The second biggest area of concern for teachers was teaching with social distancing and the logistics that went into making that happen successfully. Teachers really struggled with understanding how they were going to be able to provide PE in a physically distanced environment. Their worries centered around logistically figuring out the space that they would be able to use, as well as how 
to facilitate the use and cleaning of equipment. Teachers stated their biggest concerns were "trying to keep the kids separated, but active, and having fun safely!" (Teacher 505), or "how to teach PE while maintaining distance between kids and a safe environment" (Teacher 906). Another stated that "a concern was social distancing and face masks in a gym that is not air-conditioned" (Teacher 1270) and how that would play out with students in the classroom.

Finally, teachers were focused on safety of students. Although there were only about $11 \%$ of respondents across the United States who prioritized safety of students as their top concern, this is still about 500 teachers in total. Keeping students safe through distancing, mask wearing, and cleaning equipment was something that teachers were thinking about and concerned about heading into the fall semester. This is evidenced by comments such as, "How to follow CDC's guidelines for social distancing and keeping equipment sanitized" (Teacher 2636) or "what restrictions will need to be implemented for students and myself to stay safe" (Teacher 358). It is important to keep in mind that in May 2020, guidelines were still being developed and information about the virus was still unknown, which could have influenced the teachers' prioritization of this concern. Safety of students prior to COVID-19 largely encompassed making sure space was safe to move in, but adding a virus where teachers lacked the knowledge as well as the resources to safely contain spread among students was worrisome.

\section{Discussion}

In the spring of 2020, educational systems were forced into a halt with a series of shutdowns, and schools scrambled to move to an online environment to continue learning in some capacity (Young \& Donovan, 2020). Understanding how PE teachers experienced and perceived this shift to online learning during the COVID-19 pandemic is important as it has implications for how to successfully teach online PE in the future. This study sought to examine teachers' perceptions of their experiences as well as concerns that they had for moving forward into the next school year.

There were three themes that emerged as part of the data analysis process: Teachers' Proud Moments, Help! So Many Obstacles, and Future Challenges. Overall, teachers were proud of how they adapted, but they experienced obstacles and needed help. They also anticipated challenges for the future. It is also important to note that there were concepts that could be seen converging across all of the themes. The concepts of technology, student participation, and meeting students' needs dominated teachers' responses. Teachers viewed technology as a major barrier because many had to acquire new knowledge to be successful in implementing an online curriculum. However, technology was also noted as a source of success because once teachers were able to overcome certain barriers, they were able to use technology to successfully connect with students and provide meaningful experiences of PE and PA. This was consistent with other data collected during the pandemic around the same time by SHAPE America (SHAPE America, 2020). Teachers also demonstrated a need for continued PD on the effective use of technology in the virtual PE classroom and this follows trends in the literature around effective teaching in PE (Rink, 2013). Student participation also cut across most of the major themes. Teachers discussed participation as a barrier because they were unable to require students to participate; however, many teachers also reported that the students who did participate in their classes were very engaged and enthusiastic about the activities. Finally, meeting the needs of all students was mentioned many times across the themes. Teachers acknowledged this as one of their biggest barriers, as it was hard to meet all students' needs, whether it was providing online accommodations and modifications or simply connecting with them online or through a paper packet.

Although several physical educators felt unprepared and unsupported (SHAPE America, 2020), many rose to the occasion and worked together to provide online PE for their students. As teachers taught PE during the pandemic, there were many questions about what PE would look like in this online or hybrid format. Although there has been research conducted regarding best practices in online PE (Killian, Kinder, \& Woods, 2019), online PE was not something that existed to a large degree in most states preCOVID. In understanding how PE rolled out during the pandemic, it is important to also look to the future of online PE and how the experiences of teachers can impact how the world of online PE moves forward postpandemic. The lessons learned from these experiences teaching online will not only prepare the educational system, including PE, for future pandemics and global crises alike, but will also have long-term implications for the future of remote instruction.

The authors will use the Essential Components of PE to further consider the study's results in the context of recommended practices for quality physical education programming and to explore the implications for moving forward in an online PE environment. The Essential Components of PE is focused on four key areas: (a) policy and environment, (b) curriculum, (c) appropriate instruction, and (d) student assessment (SHAPE America, 2015). The framework is designed to help schools and districts meet the SHAPE America PE standards (SHAPE, 2013) and create well-designed PE programs that are student-centered, keep youth active, teach self-management, emphasize the knowledge and skills that youth need to be active, and are enjoyable.

Policy and environment, the first component of the framework, focuses on eight important guidelines for districts and schools to have in order to offer appropriate PE and PA experiences during the school day. Curriculum, the second component, suggests three guidelines on which to focus for appropriate PE curriculum: (a) written, sequential, and comprehensive; (b) based on the national standards and grade-level outcomes; and (c) designed specifically for a school or district and revisited in a timely manner. The third component of the framework is appropriate instruction, which focuses on four key areas including using appropriate instructional practices, being evaluated for teacher effectiveness, engaging students in moderate to vigorous PA for at least $50 \%$ of class time, and ensuring the inclusion of all students. Finally, the fourth component of the framework is student assessment. SHAPE America sets forth four key guidelines to follow which cover the areas of standards-based grading, evidence-based practices, alignment to the lesson objectives, and communicating progress to teachers and students (SHAPE America, 2015).

Policy and environment for PE is often a struggle in states and school districts as many marginalize PE and don't prioritize it the same as "core" subject areas (McKenzie \& Lounsbery, 2009; Slater, Nicholson, Chriqui, Turner, \& Chaloupka, 2012). This was no different throughout the pandemic; as teachers reported in theme two, Help! So Many Obstacles, the lack of accountability was a major obstacle to their ability to implement and carry out their PE program in an online environment. These reactions and feelings from teachers are somewhat expected as the global pandemic wreaked havoc on the world. These feelings were not exclusive to PE teachers as there was a lack of accountability in schooling across the board, with students not being required to be in 
attendance, turn in homework, or take standardize tests that are typically required (Reich et al., 2020).

As we move into a postpandemic world, it is important to keep in mind the successes and struggles of teachers in the online environment. Having a plan and policy in place for online PE at both the state and local levels is important as it will help structure and guide online PE for the future. Currently the Essential Components of $P E$ do not address policies in the online environment, but now that we know more about how teachers rolled out curricula online, maybe it is time to think about what the best policies and procedures should be for online PE both now and in the future.

Curriculum as outlined in the Essential Components of PE was not very evident in the data that were analyzed. Teachers were worried about the logistics of carrying out a curriculum and adapting curricula that they traditionally taught in a face-to-face environment. Theme 3, future challenges, discussed the need for resources to help them develop activities to teach in an online environment and the PD to teach them how to use those resources. They also struggled with meeting standards given the challenges that were presented. There was no "set curriculum" that teachers could follow to ensure they were offering quality PE. It may be time to prioritize specific standards and/or content to be taught in an online environment. This is an area that could be enhanced in the future as schools and districts work to integrate how online schooling will be applicable in the future.

Appropriate instruction was an area that teachers were working to achieve during the pandemic. Many teachers reported embracing new skills, such as teaching "live" through video software platforms, posting assignments for students to complete on their own at home, and even learning many media skills to enhance their teaching practices. The successes that teachers faced in regard to instruction, described in Theme 1, Teachers' Proud Moments, bring many new questions to the forefront. How will technology be used in PE moving forward, postpandemic? Now that teachers have been forced to learn technology skills for an online environment, will flipped classrooms be more prevalent in a traditional PE environment? Will bad weather days be nonexistent? Will PE class be structured differently, allowing more space for PA homework and holding students accountable for reaching goals of 60 min of PA per day? Previously identified shortcomings of online $\mathrm{PE}$, such as a lack of a comprehensive program and a lack of research on best practices (Daun \& Buschner, 2012; Mohnsen, 2012), may be addressed with the increased focus on remote instruction. Although many questions remain about the future, we know that, in general, teachers learned a lot more about online technologies in PE than they ever had before, and this should have implications moving forward.

Teachers also expressed a desire for PD specific to instructional strategies in an online PE environment. As discussed in Theme 2, Help! So Many Obstacles, many asked for effective ways to teach material online, how to engage students with little equipment, and so forth. There was also a general need for instructional best practices, even beyond COVID-19, as some teachers expressed the need for learning about classroom management and motivating students. This is similar to previous research by Rink et al., but should be explored more in an online environment (Rink, 2013). As districts and researchers plan to support teachers throughout the continuing pandemic as well as postpandemic, appropriate instruction in the online environment should be further investigated.

The final Essential Component of PE is assessment. Teachers reported struggling with assessment and holding students accountable during the pandemic. As described in Theme 2, Help! So Many Obstacles, this was due to various reasons including lack of participation and lack of policy requiring students to engage. Although teachers felt successful in overcoming such challenges as technology, assessment and meeting the standards were still of concern. Teachers had a hard time tracking and evaluating student participation in a virtual environment. Although this is not parallel to experiences in online PE that took place prior to the COVID-19 pandemic, it does make one wonder what objectives/ outcomes/standards should be prioritized and addressed in an online post-COVID era. There were significant barriers to reaching all students which further exacerbated the issues of assessment and holding students accountable. With levels of PA identified as already in decline at the pandemic onset (Dunton et al., 2020; Xiang, Zhang, \& Kuwahara, 2020), this is of grave concern if PE moves forward in an online or hybrid environment as many struggled to overcome this common barrier. If left unaddressed, a significant number of students could be excluded from PE experiences, or not properly assessed while participating in online PE, and this could have long-term effects on not only their health but on their academic achievement as well.

In addition, teachers called for additional PD that would focus on integrating technology, improving instructional practice, and conducting assessments in the online and hybrid PE environments. As we move forward into a postpandemic world, it will be important to provide teachers support and PD that integrates effective practices in online and hybrid teaching with common best practices in PE.

There are limitations present in this study that are important to acknowledge. First, the sample was specific to teachers who used OPEN's curriculum and signed up on their website. This is important to note as it could mean that respondents were representative only of teachers who were connected through an online community, in which case the themes that emerged might not be similar for those who are not connected with the OPEN community. In addition, survey questions were designed to improve resources and PD opportunities; therefore, there are a number of limitations with the survey including they were not theoretically informed, nor were they piloted and validated before use. Finally, this study relied only on a single source of data. However, even with multiple limitations, there are still strengths within the data that were collected and presented, including the fact that data from over 4,000 elementary and secondary teachers located in multiple regions of the United States was collected. Results should be interpreted with caution and applied where the reader sees similarities within their own context. Even with these limitations present, the authors believe this research is significant and should help inform the field of PE in understanding and implementing the essential components of PE in an online environment.

Understanding what teachers experienced during the COVID-19 pandemic is important and helps inform our thoughts around the future of $\mathrm{PE}$ and specifically online PE moving forward. Although the hope is that much will move "back to normal" in the future, the possibility exists that physical educators will be faced with this situation again and will need quality, evidence-based techniques. Ignoring this possibility and hoping that it goes away is not an option if we want to provide the best PE environment for all students. Preparing for PE in an online environment and ensuring alignment with the Essential Components of PE is important. It is comforting to know that teachers are more willing than ever to embrace an online PE environment and the implications this willingness could have for improving instruction in both online and face-to-face PE in the future is one glimmer of 
hope to take away from the terrible situation that presented itself in the spring of 2020 .

\section{Acknowledgments}

The authors thank OPENPhysEd.org for sharing their data to help tell the story of what happened during the COVID-19 pandemic. We express our deepest sympathies to all of those who were impacted by the pandemic. We are stronger together.

\section{References}

An, R. (2020). Projecting the impact of the coronavirus disease-2019 pandemic on childhood obesity in the United States: A microsimulation model. Journal of Sport and Health Sciences, 9(4), 302-312. doi:10.1016/j.jshs.2020.05.006

Daum, D.N., \& Buschner, C. (2012). The status of high school online physical education in the United States. Journal of Teaching in Physical Education, 31(1), 86-100. doi:10.1123/jtpe.31.1.86

Dunton, G.F., Do, B. \& Wang, S.D. (2020). Early effects of the COVID-19 pandemic on physical activity and sedentary behavior in children living in the U.S. BMC Public Health, 20(1), 1351. PubMed ID: 32887592 doi:10.1186/s12889-020-09429-3

Elo, S., Kaariainen, M., Kanste, O., Polkki, T., Utriainen, K., \& Kyngas, H. (2014). Qualitative content analysis: A focus of trustworthiness. SAGE Open, 4(1), 2158244014522633. doi:10.1177/21582440 14522633

Eyles, A., Gibbons, S., \& Montebruno, P. (2020). Covid-19 school shutdowns: What will they do to our children's education? London School of Economics and Political Science, London, UK. Retrieved from http://eprints.lse.ac.uk/104675/

Goad, T. \& Jones, E. (2017). Training online physical educators: A phenomenological case study. Education Research International, 2017 1-12. doi: $10.1155 / 2017 / 3757489$

Guerrero, M.D., Vanderloo, L.M., Rhodes, R.E., Faulkner, G, Moore, S.A., \& Trembley, M.S. (2020). Canadian children's and youth's adherence to the 24-h movement guidelines during the COVID-19 pandemic: A decision tree analysis. Journal of Sport and Health Sciences, 9(4), 313-321. doi:10.1016/j.jshs.2020.06.005

Jeong, H.C., \& So, W.Y. (2020). Difficulties of online physical education classes in middle and high school and an efficient operation plan to address them. International Journal of Environmental Research and Public Health, 17(19), 7279. doi:10.3390/ijerph17197279

Killian, C.M., Kinder, C.J., \& Woods, A. (2019). Online and blended instruction in K-12 physical education: A scoping review. Kinesiology Review, 8(2), 110-129. doi:10.1123/kr.2019-0003

Marshall, D.T., Shannon, D.M., \& Love, S.M. (2020). How teachers experienced the COVID-19 transition to remote instruction. Phi Delta Kappan, 102(3), 46-50. doi:10.1177/0031721720970702

McKenzie, T.L., \& Lounsbery, M.A.F. (2009). School physical education: The pill not taken. American Journal of Lifestyle Medicine, 3(3), 219-225. doi:10.1177/1559827609331562

McKenzie, T.L., \& Lounsbery, M.A.F. (2014). The pill not taken: Revisiting physical education teacher effectiveness in a public health context. Research Quarterly for Exercise and Sport, 85(3), 287-292. PubMed ID: 25141081 doi:10.1080/02701367.2014.931203

Mercier, K., Centeio, E.E., Garn, A., Erwin, H., Marttinen, R., \& Foley, J. (2021). Physical education teachers' experiences with remote instruction during the initial phase of the COVID-19 pandemic. Journal of Teaching in Physical Education, 40(2), 337-342. doi:10. 1123/jtpe.2020-0272

Mohnsen, B. (2012). Implementing online physical education. Journal of Physical Education, Recreation \& Dance, 83(2), 42-47. doi:10.1080/ 07303084.2012.10598727

Reich, J., Buttimer, C.J., Coleman, D., Colwell, R.D., Faruqi, F., \& Larke, L.R. (2020). What's Lost, What's Left, What's Next: Lessons learned from the lived experiences of teachers during the 2020 novel Coronavirus pandemic. doi:10.35542/osf.io/8exp9

Richards, K.A.R., Gaudreault, K.L., Starck, J.R., \& Woods, A.M. (2018). Physical education teachers' perceptions of perceived mattering and marginalization. Physical Education and Sport Pedagogy, 23(4), 445-459. doi:10.1080/17408989.2018.1455820

Richards, K.A.R., \& Hemphill, M. (2018). A practical guide to collaborative qualitative data analysis. Journal of Teaching in Physical Education, 37(2), 225-231. doi:10.1123/jtpe.2017-0084.

Rink, J. (2013). Measuring teacher effectiveness in physical education. Research Quarterly for Exercise and Sport, 84(4), 407-418. PubMed ID: 24592771 doi:10.1080/02701367.2013.844018

Rundle, A.G., Park, Y., Herbstman, J.B., Kinsey, E.W., \& Wang, Y.C. (2020). COVID-19-related school closings and risk of weight gain among children. Obesity, 28(6), 1008-1009. PubMed ID: 32227671 doi:10.1002/oby.22813

SHAPE America. (2013). National Standards for K-12 Physical Education. SHAPE America. Retrieved from https://www.shapeamerica. org/standards/pe/

SHAPE America. (2015). The Essential Components of Physical Education. SHAPE America. Retrieved from https://www.shapeamerica. org/upload/TheEssentialComponentsOfPhysicalEducation.pdf

SHAPE America. (2020). Survey results reveal back to school readiness and concerns of nation's health and physical education teachers. Retrieved from https://www.shapeamerica.org/pressroom/2020/ Survey_Results_Reveal_Back_to_School_Readiness_and_Concerns_ of_Nations_Health_and_PE.aspx

Slater, S.J., Nicholson, L., Chriqui, J., Turner, L., \& Chaloupka, F. (2012). The impact of state laws and district policies on physical education and recess practices in a nationally representative sample of US public elementary schools. Archives of Pediatrics and Adolescent Medicine, 166(4), 311-316. PubMed ID: 22147763 doi:10.1001/archpediatrics. 2011.1133

Williams, L. (2013). A case study of virtual physical education teachers' experiences in and perspectives of online teaching. Retrieved from https://scholarcommons.usf.edu/etd/4962/

Xiang, M., Zhang, Z., \& Kuwahara, K. (2020). Impact of COVID-19 pandemic on children and adolescents' lifestyle behavior larger than expected. Progress in Cardiovascular Disease, 63(4), 531-532. doi:10.1016/j.pcad.2020.04.013

Young, J., \& Donovan, W. (2020). Shifting to online learning in the COVID-19 Spring. Pioneer Education. Retrieved from https://eric.ed. gov/?id=ED604252 